\title{
Implementation of Corporate Social Responsibility (CSR) Menteng Mitra Afia Hospital In Educating The Public
}

\author{
Henilia Yulita ${ }^{1}$, Koerniawan Hidajat ${ }^{2}$ \\ ${ }^{12}$ Bunda Mulia University \\ Correspondent: hyulita@,bundamulia.ac.id
}

Submitted : September 22, 2020 Revised : October 15, 2020 Published : October 31, 2020

\begin{abstract}
The research focus is on the activities of Menteng Mitra Afia Hospital in educating public health to the context of public health education itself. This research uses a qualitative paradigm, a paradigm that aims to understand a social phenomenon, as a research approach with case study method. The subject of the research is Menteng Mitra Afia Hospital. Object of the research is corporate social responsibility (CSR) and health education. This research answers how the implementation of (CSR) RS. Menteng Mitra Afia educates the public during a new normal co-19 pandemic. The result of the research are: The Infection Prevention and Control Training (PPI) was held on September 27, 2019; The BPJS - Day 2020 on Tuesday, February 11, 2020; Inauguration of Central Jakarta DPK-PPNI 2020 on February 5, 2020; and the last was Empirical Implementation of Social Responsibility (CSR) with Webinar on July 11, 2020. The results of the speaker material responses in this webinar show that on average $70 \%$ (percent) of the 512 participating webinar communities are very responsive, or very good (SB) assessing the material provided by filling out questionnaires in a form such as a Likert scale.
\end{abstract}

Keywords: Corporate Social Responsibility, Community Development, Partnership and Community Development Program

\section{INTRODUCTION}

Health workers are at the front line of the COVID-19 outbreak response and as such are exposed to hazards that put them at risk of infection. Hazards include pathogen exposure, long working hours, psychological distress, fatigue, occupational burnout, stigma, and physical and psychological violence. This document highlights the rights and responsibilities of health workers, including the specific measures needed to protect occupational safety and health. The hospital said on Thursday the number of patients kept increasing in recent days to more than 1,000 currently. If the trend continues, the makeshift hospital will soon reach its limit, but a plan to scale up capacity is underway. (WHO, 2020).

According to the Law on Hospitals, what is meant by the social function of hospitals is to carry out social functions, among others, by providing facilities for poor patients, emergency services without down payment, free ambulances, disaster victims and extraordinary events, or social services for mission's humanity. Given this understanding, the social function of hospitals is "only" philanthropic or generosity. Meanwhile, according to the Law on PTs, actually those that are required to carry out CSR activities are PTs engaged in or relating to the management of natural resources (such as mining, petroleum, coal, plantations such as palm oil, sugar cane, etc.).

Corporate social responsibility specifically refers to company operations and ensures the longterm sustainability of the company's business. The relationship between the company and the community must be harmonious so that the company benefits the community. Corporate Social Responsibility (CSR) is a commitment from a business or company to behave ethically and 
contribute to economic development that is supported, while improving the quality of life of employees and livestock, local communities, and the wider community.

CSR is now regulated in several regulations which are binding so that 'certain companies' are required to carry out their social responsibilities. There is a long process related to the history of the emergence of regulations related to CSR or programs that were initially identical to the terms Community Development (CD), Partnership and Community Development Program (PKBL).

The research question "How is the implementation of social responsibility (CSR) RS. Menteng Mitra Afia educates the public during a new normal co-19 pandemic through a webinar?" The purpose of this research is to describe the implementation of the social responsibility of Menteng Mitra Afia Hospital to educate the public during a new normal co-19 pandemic through a webinar.

Corporate Social Responsibility (CSR) is a phenomenon and strategy used by a company to accommodate the needs and interests of its stakeholders. CSR began in an era where awareness of long-term corporate sustainability is more important than mere company profitability. CSR (Corporate Social Responsibility) is a concept or action taken by a company as a form of corporate responsibility towards the social and the environment in which the company is located. The CSR benefits for the community: (1) Increased welfare of the surrounding community and environmental sustainability; (2) There are scholarships for underprivileged children in the area; (3) Increased maintenance of public facilities; and (4) The existence of village development / community facilities that are social and useful for many communities, especially the community around the company is located.

Corporate Social Responsibility (CSR) represented through Public Relation which aims to instill and gain understanding, goodwill, and trust from public organizations both internal and external by establishing relationships to ultimately be able to create positive public opinion for the continuation of the organization's life.

CSR benefits for the company: (1) Improve company image; (2) Develop cooperation with other companies; (3) Strengthening the company's brands in the eyes of the public; (4) Differentiate the company from its competitors; and (5) Providing innovation for companies.

This is what drives CSR to emerge with the earliest and simplest program, which is a caritative assistance (giving donations that often do not educate, because it creates dependency) or philanthropy (the company's concern for victims of natural disasters). As a form of corporate communication, PR is very supportive to intensify the involvement and participation of communities around the company that are targeted by the CSR program.

CSR (Corporate Social Responsibility) functions include the following: (1) Social Permit to Operate; (2) CSR Can Improve Relationships with Regulators; (3) CSR Increases Employee Morale and Productivity; (4) CSR Facilitates Access to Market; (5) CSR Can Improve Relationships with Stakeholders; (6) CSR Enlarges Opportunities to Get Awards; (7) CSR Can Minimize Company Business Risk; (8) CSR Can Widen Access to Resources; and (9) CRS Can Minimize Expenditures.

Health education in the sense of education. in general, any planned effort to influence other people, whether individuals, groups, or the community, so that they do what is expected by education practitioners or health promotion. Carrying out social responsibility normatively is a moral obligation for any type of company. When a company as a new community intervenes in 
Implementation of Corporate Social Responsibility (CSR) Menteng Mitra Afia Hospital In Educating The Public Yulita \& Hidajat

local communities, it has become imperative to adapt and contribute, because its existence has had both positive and negative impacts.

\section{METHODS}

The study was conducted using the case study method (case study), in which the researcher explored a case bound by time and activity (program, event, process, institution, or social group) and collected detailed information using various data collection procedures over a specific period (Creswell, 1994).

This method is suitable for this study because researchers cannot manipulate the behavior of those involved in the activities under study (Yin, 2003). In addition, Yin also mentioned that this method is also used to understand cases that cannot be separated from the context, in this case the activities of Menteng Mitra Afia Hospital in educating public health are bound to the context of public health education itself.

Based on the guiding hypothesis made, the researcher believes that there is a relationship between the following two concepts, namely the role of Menteng Mitra Afia Hospital and public health education as an implementation of Corporate Responsibility.

Considering the purpose of the research is to explain each concept and understand the implementation of Corporate Social Responsibility as a result of the relationship between the concepts, the case study method used in this research is an explanatory case study, which explains the relationships that are considered causal in the intervention real life that is too complex for survey or experimental strategies (Yin, 2003).

This research was conducted at Menteng Mitra Afia Hospital which is located at Jl. Kali Pasir No.9, RW.10, Kb. Betel, Kec. Menteng, City of Central Jakarta, Special Capital Region of Jakarta 10340. In accordance with the research objectives, this location was chosen because researchers wanted to find out how the implementation of Corporate Social Responsibility through WEBINAR was conducted to educate the public, especially during the 19th century to the new normal.

The method of determining informants used by researchers is purposive sampling, ie informants are determined by researchers intentionally based on the objectives to be achieved. In addition, the reason why informants are determined in advance, not randomly, is to obtain a wealth of more detailed and in-depth data held by certain informants (Ezzy, 2002). The main concepts of this research is about implementation of Corporate Social Responsibility as educating the public through a webinar at Menteng Mitra Afia Hospital.

Primary data is data obtained directly from data sources, namely through: 1 . Director of Menteng Mitra Afia Hospital: dr. Enrico Adhitya Rinaldi M.A.R.S, MH, CHRM; 2. People who feel the Corporate Responsibility program. Secondary data is data obtained indirectly to support this research, namely primary data obtained by other people or primary data that has been further processed and presented either by primary data collectors or by other parties who are generally presented in the form of tables or tables. diagrams. Secondary data was obtained through documents or publication notes from Menteng Mitra Afia Hospital and scientific writings in books, journals, newspapers and magazines. Document studies are conducted to obtain preliminary data needed by researchers. The data used as preliminary research data are secondary data obtained through various media, such as state documents, books, journals, research results, papers, limited publications, newspapers, and articles on the website. 
Some information obtained from observations are space (place), actors, activities, objects, actions, events, or events, time, and feelings. The reason researchers conduct observations is to present a realistic picture of behavior or events, to answer questions, to help understand human behavior, and for evaluation that is measuring certain aspects of doing feedback on these measurements. The researcher made direct observations of non-participants because relevant behavior was available at the study site to be observed. Researchers only systematically observe and record the symptoms in the field.

The interview technique used is in-depth interviews with informants to ask informants' views about certain things that are useful for answering research questions. Alston \& Bowles (1998) suggested that in-depth interviews aim to look at social phenomena that are examined from the view of informants, to investigate their thoughts and feelings and to thoroughly understand their point of view.

In order to provide research on research with the nature of purposive sampling, this study also uses quota sampling, citing limited time, cost and energy, but does not leave sample representativeness.

Researchers use qualitative content analysis techniques (qualitative content analysis) to draw conclusions and answer research questions. This technique not only analyzes the tangible content of data, but also the context information from that data which is referred to as latent information (Mayring, 2000).

The results of observation and analysis of documents can be put in the same file to support understanding of interview transcript data. The data is then tried to find its meaning/ interpretation. In interpreting, researchers must hold on to the coherence between the research objectives and the results of coding data.

To ensure accuracy and ensure the ability to generalize and know the possibility of research replication, it is important for researchers to express the validity and reliability of this study.

\section{RESULTS AND DISCUSSION}

Hospital Menteng Mitra Afia is a Legal Entity, the Company was established in early 1997, Menteng Mitra Afia Hospital is known as a Special Hospital for Neurology and Psychiatry. Over time, keep abreast of the development and needs of its customers, then change itself into a General Hospital.

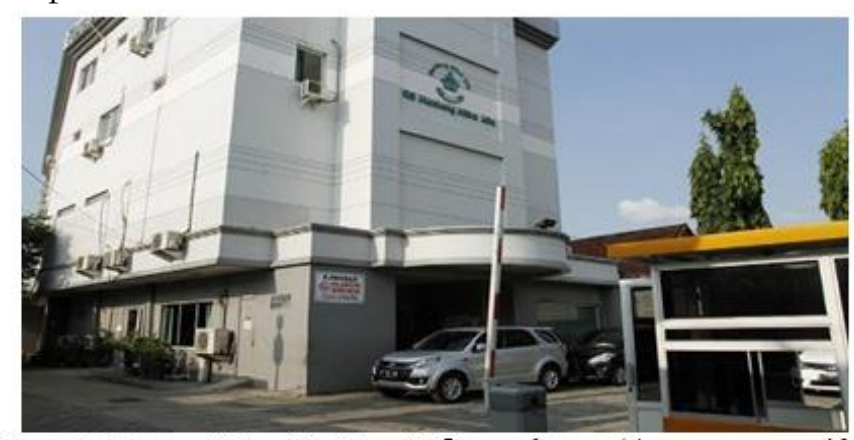

Hospital Menteng Mitra Afia in order to reach the community already has services in the form of an Emergency Room 24 Hours per 7 Days, Hotline (021) 3146309 and SPGDT (Integrated Hospital Management System) 08827677-9064. Introducing Hospitals is not like introducing an institution with market provides more benefits, but

Figure 1. Menteng Mitra Afia Hospital Source: htpps: //www.rsmma.co.id more on community services as health user services, RS. Menteng Mitra Afia already uses a website
service with a URL address (Uniform Resource Locator) is a series of characters according to a certain standard format, which is used to indicate the address of a source such as documents and 
images on the Internet. URL is a basic innovation for the development of Internet history, namely: htpps: //www.rsmma.co.id.

The vision of Menteng Mitra Afia Hospital is "Become A Hospital That Gives Quality, Reliable Service, In Jakarta Central Year 2023 Administs The Affordable Satisfaction And Receiving Barokah From God SWT." The motto that is always carried to improve the vision and mission of the Menteng Mitra Afia Hospital is "Never Stop To Become Better".

Menteng Mitra Afia Hospital has facilities as owned by other General Hospitals, such as: (1) VIP Treatment Room; (2) Special Treatment Room; (3) reatment Rooms I, II, and III; (4) Laboratory (Pathology, Anatomy, Microbiology, Clinical Pathology); (5) Radiology; (6) Pharmacy; (7) Physiotherapy; and (8) Emergency Installation.

People who visit do health control in the hospital. Menteng Mitra Afia with registration schedule for outpatient care: Morning starting at $07.00 \mathrm{WIB}$ until $11.00 \mathrm{WIB}$, and in the afternoon starting at 13.00 WIB until 18.00 WIB. The average per day of the hospital. Menteng Mitra Afia serves \pm 50 to 250 community visits per day on an outpatient basis.

Hospital Menteng Mitra Afia has a specialty compared to other public hospitals, although in the midst of a very congested community, this four-story building has superior health facilities including: a. Eye examination; b. Hemodialis; c. Midwifery; and d. Medical Rehab. Menteng Mitra Afia Hospital even though it is a Type A Hospital, but all standard facilities have been fulfilled as a public hospital, such as the operating room, echocardiography room, physiotherapy room, special room for hemodial treatment or dialysis, and so on. Remembering the first hospital. Menteng Mitra Afia is not serving the general public but is a Special Hospital for Neurology and Psychiatry.

Menteng Mitra Afia Hospital receives referrals of various health insurance ranging from "red plate" to private, along with a list of Insurance and URL-Web address (Universal Resource Locator) of insurance in collaboration with the Menteng Mitra Afia Hospital: 1. BPJS Health; 2. AdMedika; 3. Nayaka; 4. Jasindo; 5. Tokio Marine Insurance Group; 6. AXA; 7. Reliance Insurance; 8. MNC Life; 9. ABDA Insurance; 10. Wana Artha Life; 11. Sompo Insurance; 12. Astra Insurance; 13. BCA Life; 14. Allianz; 15. Avrist; 16. Owlexa Insurance; 17. Generali; 18. AIA; 19. FWD Life Insurance; 20. Mandiri In Health; 21. Life Insurance Simas; 22. Sinarmas; 23. MSIG Life; 24. CAR Life Insurance; 25. Cigna; 26. Hanwha Life; 27. Indosurya Life; 28. Intra Asia Insurance; 29. CHUBB; 30. Medicillin my health insurance.

Menteng Mitra Afia Hospital has a doctor's appointment schedule, both general practitioners and specialist doctors. The doctor at the hospital. MMA (Menteng Mitra Afia) has a schedule from Monday to Saturday. The registration method for visiting doctors at the Polyclinic is a specialist doctor using on-line and BPJS lists.

\section{CSR Activities in the Menteng Mitra Afia Hospital}

In order to increase the trust of Menteng Mitra Afia Hospital, it is implementing health service improvements, especially for patients as customers. Various improvements in terms of management, personnel (medical and non-medical officers), medical equipment, investors were brought in, this continuous improvement paid off in 2019, RS. Menteng Mitra Afia includes the 2019 Si-Intan Award nominees (Patient Dose Data Information System) 2019, organized by the Nuclear Energy Supervisory Agency (BAPETEN) with the theme "Joint Synergy in Radiation Safety Protection for Radiology Patients". 
The implementation of CSR (Corporate social Responsibility) at Menteng Mitra Afia Hospital is in principle adjusted to the internal program of the Hospital. Menteng Mitra Afia itself, where the hospital. Menteng Mitra Afia as a Private Hospital that plays a role in assisting the Government in carrying out public health, both the environment around the hospital and making patients referral to other hospitals. Many programs are carried out in educating the public in hospitals. Menteng Mitra Afia, including activities:

a) PPI Training - 2019

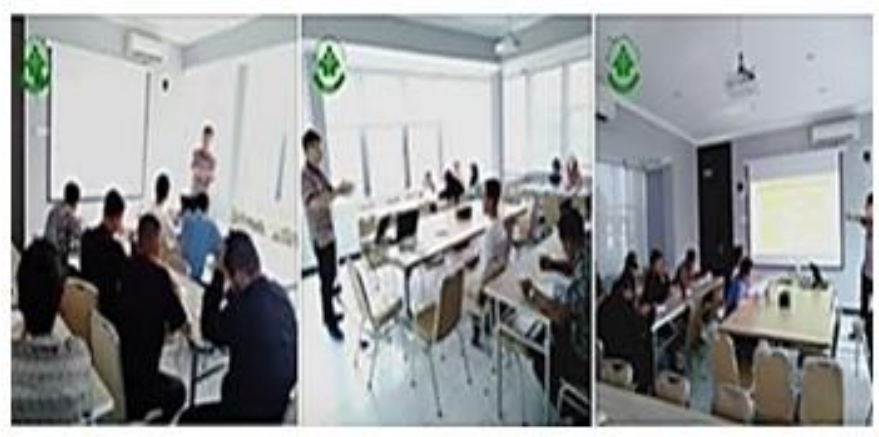

Picture 2. PPI Training - 2019

Source: htpps: //www.rsmma.co.id.

The Infection Prevention and Control Training (PPI) was held on September 27, 2019 in order to improve the performance of employees, especially paramedics and nonparamedics who served in the hospital. Menteng Mitra Afia deals with the prevention of infection when carrying out tasks or when carrying out operations in the patient room. The event was hosted by Dr. Yudha Indrawirawan, SpPK as chairman of the PPI committee at MMA General Hospital.

This infection prevention and control training material is about hand hygiene, how to properly wash hands, use PPE (Personal Protective Equipment), environmental control, cough ethics, and hospital waste management which is divided into 3 (three) parts, namely: infectious, noninfectious and general waste. In addition to the material that is important in carrying out paramedic tasks also get interesting fun games during the training.

\section{b) BPJS - DAY 2020}

Speaking of the JKN-KIS program, the implementation of the National Health Insurance Program (JKN-KIS) was implemented since January 1, 2014, and has an impact on public health services. JKN-KIS opens greater access to the community to get basic health services. After running for almost 3 years, it turns out that the JKN-KIS program not only impacts health services but also the economy.

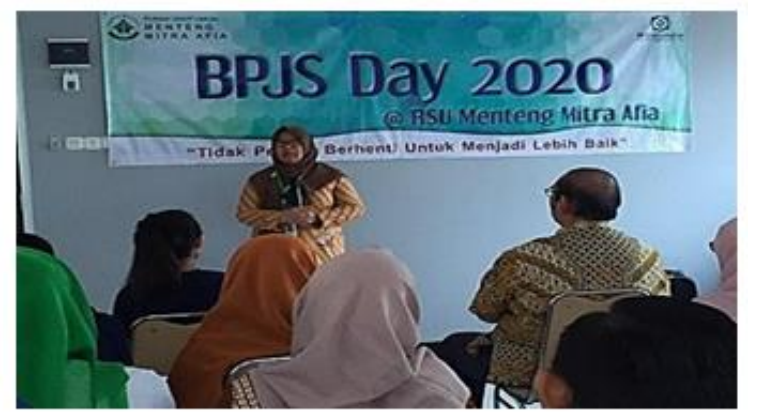

Picture 3. BPJS - Day - 2020 Source: htpps: //www.rsmma.co.id.

Menteng Mitra Afia Hospital supports this government program as part of improving public health services. BPJS - Day held at the hospital. Menteng Mitra Afia on Tuesday, February 11, 2020, was held in the hospital meeting room. Menteng Mitra Afia brought in the Head of the Central Jakarta BPJS Health Branch, Siti Farida Hanoum, who was also attended by hospital leaders. Menteng Mitra Afia and paramedics, especially those related to BPJS service applications in internal hospitals. Menteng Mitra Afia. The BPJS - Day 2020 activity is an appreciation for employees, especially paramedics and non-paramedics who relate to parts or tasks of service to the community in order to understand and upgrade knowledge as a form of health education methods in Notoadmodjo (2012) that health education is based on targets to be achieved with educational methods health by group. 


\section{c) Inauguration of Central Jakarta DPK-PPNI 2020}

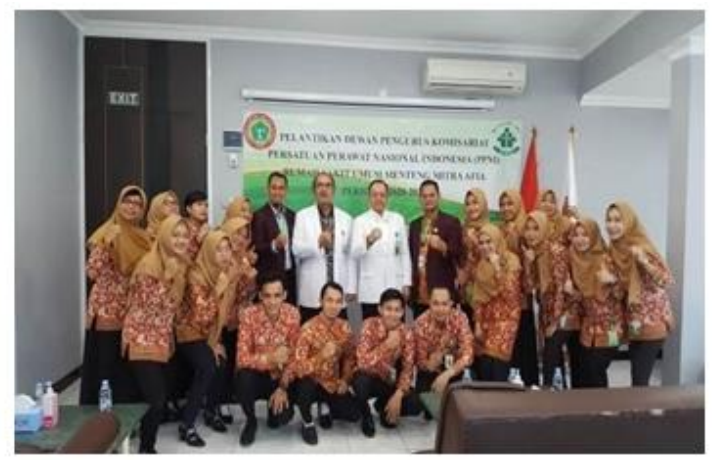

Picture 4. Inauguration of Central Jakarta DPK- PPNI 2020 Source: htpps: //www.rsmma.co.id.

Previously on February 5, 2020 RS. Menteng Mitra Afia carried out the inauguration of the Central Jakarta Indonesian National Nurse Commissariat Board (DPK-PPNI), in the Meeting Room Room, attended by the Managing Director of the Hospital. Menteng Mitra Afia Mr. dr. Enrico A. Rinaldi, MARS., Dr. Kunto Raharjo, SpAn-KIC as Deputy Medical Director, and Ms. Dian Fitriani, S.Psi as HRD MH manager, Head of Nursing Hospital. Menteng Mitra Afia Ibu Ns. Siti Nurhaeni Hasnah, S.Kep, Chairperson of the Central Jakarta PPNI DPD Mrs. Ns. Nana Sl, M.Kep, SP.Kep, KMm., Secretary of the Central Jakarta PPNI DPD Mr Ns. Mulyana, S.Kep. In the event Arnofra Hutagaol, Amd. Kep was also appointed as the elected chairman of the PPNI Menteng Mitra Afia Hospital.

The front guard in the health sector is expected to be able to carry out public health service nurses in accordance with the standards or SOP (standard Operation Procedure) that have been set both world health standards, national health standards and internal health standards of the hospital. Menteng Mitra Afia. Professionalism of nurses with the support of the organization formed is expected to further optimize and strengthen the identity of nursing to provide the best health services to the community. During the covid pandemic 19, with the implementation of new normal, it will change all behavioral and paramedical responsibilities, especially nurses provide health education for themselves and the community as patients in the environment of Menteng Mitra Afia hospital.

\section{d) Empirical Implementation of Social Responsibility (CSR) with Webinars}

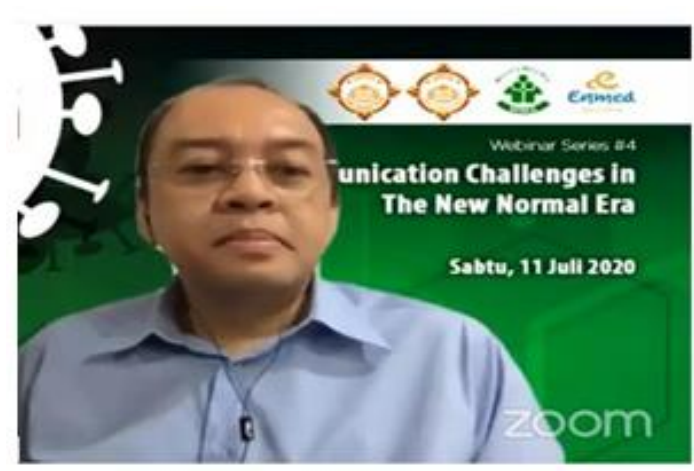

Picture 5. Webinar Health Communication Source:

https://www.youtube.com/watch?v=Lf82IMDfRp M\&feature $=$ youtu.be

Education to the public is not only done through direct action but also carried out through online such as Webinars (Web- Seminars) with the theme "HEALTH COMMUNICATION CHALANGES IN THE NEW NORMAL ERA", dr. Enrico A. Rinaldi, MARS., MH as Managing Director of the Hospital. Menteng Mitra Afia as a speaker spoke about "Challenges, Realities \& Solutions in the Covid-19 Pandemic Period in Health Communication".

This webinar, which was held by the Sahid University Jakarta Postgraduate School, on July 11, 2020, was originally attended by 512 participants with Friday registration information, at 3:31 pm West Indonesia Time. Guided by Moderator Ms. Henilia Yulita, SE, MM, M.I.Kom as the lead researcher of this study.

This webinar is part of running humanitarian services, Menteng Mitra Afia Hospital as a stakeholder for the community, especially those who need health services (patients), is the main stakeholder. Chariri and Ghazali (2007, p.32) said that companies are not entities that only operate for their own interests but must provide benefits for their stakeholders (shareholders, creditors, consumers, suppliers, governments, communities, analysts and other parties). Sahid Jakarta University Postgraduate School is part of stakeholders who benefit hospitals. Menteng Mitra Afia 
Hospital in the organizing pattern of educating the community mainly as a manifestation of the implementation of "mandatory" social responsibility.

The most possible means of implementing social responsibility (CSR) and in accordance with government regulations regarding the existence of the covid pandemic 19 outbreak, where antivirus has not yet been found, and the community is demanded to live side by side with covid 19 itself, which is called new normal, then the government uses a program in effect throughout Indonesia PSBB (Large-Scale Social Restrictions) is implemented during the longest incubation period and can be extended if there is evidence of distribution.

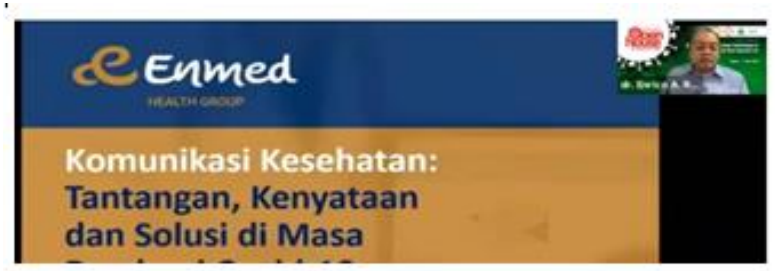

Picture 5. Presentation dr. Enrico M.A.R.S., M.H., CHRM Source:

https://www.youtube.com/watch?v=Lf82IMDfRpM\&feature=y outu.be
The impact of the pandemic from Wuhan was extraordinary in all sectors of life, dr. Enrico A. Rinaldi, M.A.R.S., M.H., CHRM said that new normal or new habits as Alternative Exit Strategies in order to move back in the community. $\mathrm{He}$ in his presentation stated health communication. Health communication is a sense of crisis from physical, mental and social

health. He even reminded that health communication especially must be someone who is competent to communicate or who is talking about this health communication, or about this news.

He explained, citing the opinion of Seeger \& Reynolds that a health communication person must understand critical patterns to help anticipate problems and prepare responses. Although each crisis has its uniqueness, of course there is a common pattern in every crisis. This society actually really needs clear communication with the hope and scholarship that can be accounted for dr. Enrico A. Rinaldi, M.A.R S. Enrico as Community Resilience, "COMMUNITY RESILIENCE is the sustained ability of a community to use available resources (energy, communication, transportation, food, etc.) to respond to, withstand, and recover from adverse situations (eg economic collapse to global catastrophic risks ) ". Bosher, Lee; Chmutina, Ksenia (3 April 2017). Out of the box thinking is no longer used but thinking "What We Need Is No BoX Thinking" is used in overcoming and educating the public, now with very unfavorable conditions according to dr. Enrico must think What We Need Is No BOX ... Thinking is not enough by creatively looking from a different way outside of the standard, that the hospital is collapsing, what must be done is collaboration as a mandatory requirement that all scholars are involved from the government and especially the community in implementing health protocols, if not covid 19 disease in the community will get worse. Health does not only belong to health professionals such as doctors and nurses, but it belongs to all. While the task required by a health communicator is to offer the information needed and fight harmful behavior.

The webinar event was attended by 306 people with Friday registration information, at 3:31 pm on July 10, 2020, then increased to 512 participants with time, especially before 9:30 a.m. July 11, 2020 when the Webinar event took place, from information gathered by the first researcher (the head of this study) was delivered through WhatsApp to the second researcher (research member) on July 12, 2020 after the event was finished. The profile of the participants of this Webinar the committee received a response of 512 people based on the mobile number of the participants who entered the committee. 
Implementation of Corporate Social Responsibility (CSR) Menteng Mitra Afia Hospital In Educating The Public Yulita \& Hidajat

Table 1.

Webinar Participant Responses

\begin{tabular}{c|c|c|c}
\hline No & Response & Amount & Persentase \\
\hline 1 & Increase knowledge & 9 & $\mathbf{1 9 , 6 4 \%}$ \\
\hline 2 & Insight & 10 & $\mathbf{1 9 , 9 2 \%}$ \\
\hline 3 & Miscellaneous Responses & 31 & $\mathbf{6 0 , 7 4 \%}$ \\
\hline \multicolumn{2}{|c}{ Amount } & $\mathbf{5 1}$ & $\mathbf{1 0 0}$ \\
\hline
\end{tabular}

Source: Primer data (2020)

Based on Table 1 above, it can be seen that the responses of participants who were collected by researchers from the webinar committee, unstructured questionnaires asked "what positive things did you get after participating in this webinar?" of the 512 community respondents participating in the webinar, 99 people or 19,33\% (percent) claimed that the Webinar that was held was able to provide additional knowledge to the general public, whether as participants, health observers, or the possibility of patients who could see or even hear directly broadcast via health education methods online approach.

As many as 102 people or $19.92 \%$ (percent) of participants said that this Webinar was very insightful, especially felt by participants who took part in this new normal era about communication during the pandemic and health aspects. Even one of the participants/community concerned about health stated that they added insight into hospital management related to Covid-19. The responses of other participants who were no less interesting were beyond adding more knowledge and insight with a variety of other responses totaling $60.74 \%$ (percent) or 311 participants/general publics who took part in this Webinar.

Some responses from the community participants of this webinar, which researchers gathered include, among others, the opinion of Heri Susanto from the USAHID Postgraduate School who participated in this webinar, among others, stating that the positive things obtained were about how to respond to communication issues over reporting that were not necessarily true. While other participants namely Kurnia Kasanah responded positively to this webinar with a statement wanting to know how to communicate well and the prospects of the telemedicine business going forward.

Budi Rahayu stated that following this webinar would be more careful in using social media (social media). Similar to Budi Kuncoro's opinion, from STAIAN NADWAH Kuala Tungkal Jambi, this webinar is very positive in the sense of knowing how to use social media (social media) properly. Other views such as Dr. Amnur, R Kayo, MKM from the Ministry of Health's Pusdatin as a webinar participant responded by following the webinar to find out more in detail about the importance of good communication between doctors and patients and public communication.

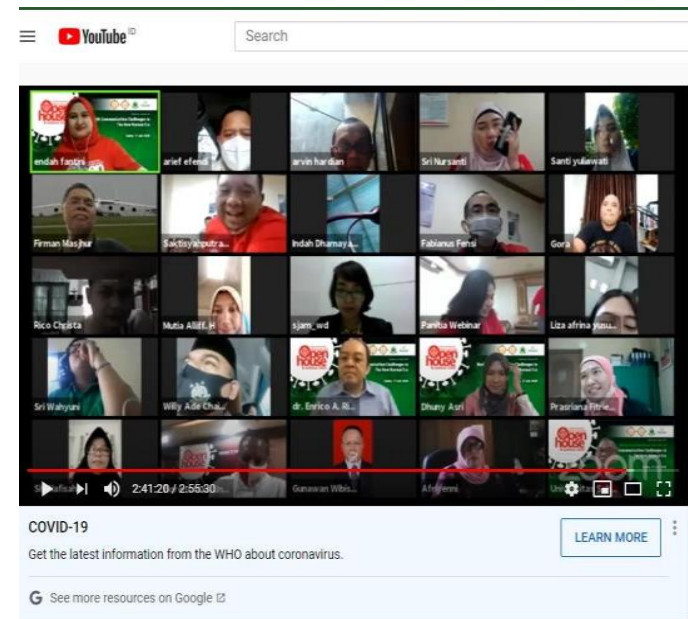

What is unique from Baso Salahudin, IAIM, Sinjai following this webinar will be to increase relations. In principle, the webinar that was held with other responses reached more than half of the participants giving positive responses to this webinar event.

The material presented by the speaker in this 
webinar, concluded that a very good response was obtained from the participating communities with the webinar method chosen in order to educate the public about health, on average if more than $70 \%$ (percent) of the participants of all webinar participants stated the material delivered very well (SB). While the public who stated the material presented by these speakers the criteria of good (B) on average based on data processed by researchers amounted to above $20 \%$ (percent), medium criteria (S) of 4 (four) speakers of this webinar on average under $2 \%$ (percent). Not good criteria (TB) from 4 (four) speakers averaged under 1\% (percent).

\section{CONCLUSION}

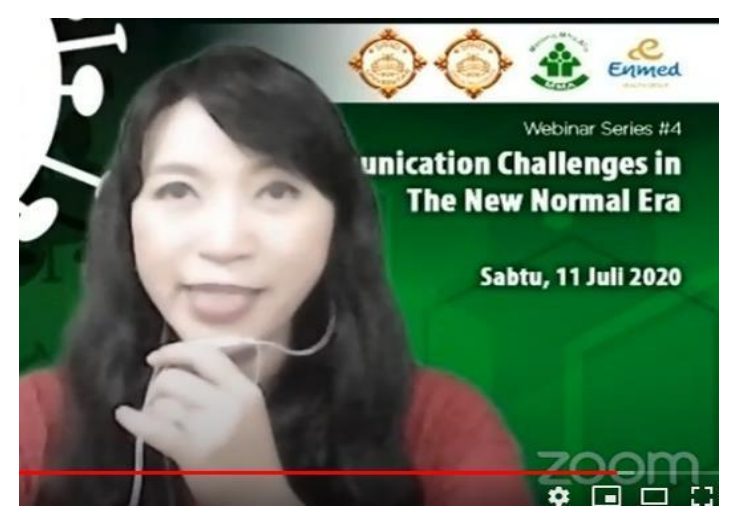

The moderator and head of this research who was directly involved in this webinar concluded that health communication during the 19th pandemic underwent many problems with a lot of information coming in that was difficult to contain, a lot of noise in the news and the beginning of the government was not ready to deny it.

Everyone talked about health and forwarding messages and even adding to those messages and some who are not competent, especially in

friendship media such as in Whatshapp group usually even add to the problem, the fact must be denied by health communicators who are fast and precise, and people who are competent to speak in health, so that it is needed for medical treatment at this time needed in the field as the front guard in the service also the delivery of accurate, accurate and precise information in accordance with his knowledge to the public. When talking health communication all must be done together and collaborate, so as not to blame each other or blame the situation and we must eliminate each other's selfishness in order to be together against the pandemic.

The final result of the speaker material in this webinar then concluded that health communication is very positive and negative impact, because messages of information and communication that are widely spread in the community must be given by people who are competent, especially talking about health, so that people receive information, especially about health the covid pandemic 19 with new normal can be quickly, accurately, carefully and precisely accepted.

The results of the community response as webinar participants amounted to 512 respondents distributing unstructured questionnaires about the question whether positive things obtained after following this webinar? with 504 people seen, the health education method with webinars is associated with social responsibility educating the public a variety of responses, to increase knowledge by 19, 33\% (percent) and add insight into the community of webinar participants as 19, $92 \%$ (percent) while other responses with positive glasses by $60.74 \%$ (percent). All responses from the community as participants in the webinar stated positively the holding of this webinar.

The empathy of the community as participants in this webinar is very supportive of the existence of educating the community in the implementation of the CSR social responsibility of the Menteng Mitra Afia Hospital through the main informant, dr. Enrico A. Rinaldi, MARS., MH, CHRM. The response from the community as participants in this webinar was evident in the YouTube recorded.

The results of the speaker material responses in this webinar show that on average $70 \%$ (percent) of the 512 participating webinar communities are very responsive, or very good (SB) 
assessing the material provided by filling out questionnaires in a form such as a Likert scale. The webinar that was held in the context of educating the community was in accordance with their professional abilities as evidenced by the community's response as a webinar participant, only under $2 \%$ (percent) stated that the material of the webinar speaker was (S), and only under $1 \%$ (percent) stated that it was not good (TB). The pattern of organizing this webinar actually met the criteria by forming an organizing committee, and choosing competent speakers was just a matter of participants' delay, duration, and networking being an obstacle.

\section{REFERRENCES}

Available at: https://www.who.int/publications/i/item/coronavirus-disease-(covid-19)outbreak-rights-roles-and-responsibilities-of-health-workers-including-key-considerationsfor-occupational-safety-and-health [Accessed 28 Juli 2020].

Ackerman, RW dan Bauer, RA (1976), Tanggung Jawab Sosial Perusahaan: Dilema Modern,

Bavaria, J. (2005), "Wal Mart: kepemimpinan abad kedua puluh satu?”, The Independent, 25 Oktober.

Bowen, HR (1953), Tanggung Jawab Sosial Pengusaha, Harper, New York, NY. Carroll, AB (1979), "Model konseptual tiga dimensi kinerja perusahaan", Academy Morissan, M.A, 2008, Manajemen Public Relations Strategi Menjadi Humas Profesional, Perusahaan Penerbitan Reston, Reston, VA. Review Manajemen, Vol. 4 No. 4, hlm. 497-505.

Reza Rahman (2009) CSR antara Teori dan Kenyataan, Yogyakarta: MedPress, hal. 73.

Sr. Maria Assumpta Rumanti OSF (2002) Dasar-dasar Public Relations Teori dan Praktek, Jakarta. WHO, 2020. Coronavirus disease (COVID-19) outbreak: rights,roles and responsibilities of health workers, including key considerations for occupational safety and health. [Online]

bttps:/ jurnal.ugm.ac.id/bkm/article/view/40506/23089

http://journal.unika.ac.id/index.php/shk/article/view/781

https://jurnal.uns.ac.id/privatlaw/article/view/25598 